\title{
Comprometimento organizacional e satisfação no trabalho: estudo com funcionários do CRAS de Borborema-PB
}

\section{Organizational commitment and satisfaction at work: a study with CRAS employees from Borborema-PB}

Cíntia Bianca Amorim de Oliveira ${ }^{1}$ Erika Fontes da Silva ${ }^{2}$ Filipe Fontes da Silva ${ }^{3}$ Raissa Dália Paulino ${ }^{4}$

\footnotetext{
1 Universidade Federal da Paraíba - UFPB cintiabianca20@gmail.com

2 Universidade Federal da Paraíba - UFPB eryka_fontes@hotmail.com

3 Universidade Federal da Paraíba - UFPB fellipe-fontes@hotmail.com

4 Universidade Federal da Paraíba - UFPB raissa@cchsa.ufpb.br
}

\section{Resumo}

Este estudo objetiva analisar a influência da satisfação no trabalho no comprometimento organizacional dos servidores públicos do CRAS de Borborema- PB, sendo caracterizado quanto aos fins, como pesquisa descritiva; aos meios, uma pesquisa bibliográfica e um estudo de caso, com abordagem quantitativa. O estudo utilizou instrumentos desenvolvidos e validados no Brasil, para medir a satisfação a Escala de Satisfação no Trabalho (EST) e para o comprometimento organizacional, as versões nacionais das três bases do comprometimento conceituadas por Meyer e Allen (1990): Comprometimento Organizacional Afetivo (ECOA), Comprometimento Organizacional Calculativo (ECOC) e Comprometimento Organizacional Normativo (ECON) todas as escalas de autoria de Siqueira (2008). Os resultados revelaram o nível de satisfação dos servidores com o trabalho e níveis de satisfação para cada dimensão, como também o comprometimento organizacional predominante na instituição. De modo geral, constatouse a correlação positiva entre a satisfação no trabalho e as três bases do comprometimento organizacional.

Palavras-chave: Satisfação no Trabalho. Comprometimento Organizacional. Servidores Públicos.

\section{Abstract}

This study aims to analyze the influence of job satisfaction on the organizational commitment of Borborema-PB's CRAS civil servants, being characterized as a descriptive research; to the media, a bibliographic research and a case study, with a quantitative approach. The study utilized instruments developed and validated in Brazil to measure the satisfaction of the Work Satisfaction Scale (EST) and organizational commitment, the national versions of the three bases of commitment, conceptualized by Meyer and Allen (1990): Affective Organizational Commitment ECOA), Organizational Compensation Calculation (ECOC) and Normative Organizational Commitment (ECON) all scales of authorship of Siqueira (2008). The results revealed the level of server satisfaction with work and levels of satisfaction for each dimension, as well as the predominant organizational commitment in the institution. In general, the positive correlation between job satisfaction and the three bases of organizational commitment was verified.

Keywords: Work satisfaction. Organizational Commitment. Public Servers. 


\section{Introdução}

Partindo do pressuposto de que, com a instabilidade no cenário atual, as organizações necessitam, cada vez mais, de fatores que lhes concedam um diferencial competitivo, a gestão com pessoas vem sendo uma forte influência para esse diferencial. De acordo com Hedler e Castro (2015), com a valorização do conhecimento, as pessoas têm se tornado o mais importante elemento dos processos organizacionais. Desse modo, a boa gestão das competências do patrimônio humano está associada à sobrevivência da organização.

O setor público brasileiro, muitas vezes, se transformou em cenários de incidentes, observados em várias mídias de comunicação, sendo importante às organizações públicas e privadas políticas de gestão com pessoas que possam favorecer a permanência de profissionais satisfeitos e comprometidos para enfrentarem ambientes de constantes mudanças, que exigem certas competências dos colaboradores. Bergamini (2008) afirma que a carência de conhecimento técnico, muitas vezes, não seria a causa do fracasso da maioria das empresas, mas sim, a maneira como se lida com as pessoas.

Portanto, funcionários com elevado grau de contentamento podem ser de grande valia para uma organização, tendo em vista que a satisfação no trabalho está associada a diversos estudos como envolvimento, desempenho, produtividade, comunicação, saúde, rotatividade e absenteísmo (Azevedo \& Egito, 2012 como citado em Hedler \& Castro, 2015; Bion, 2004; Davis \& Newstrom, 2004; Robbins, 2002; Spector, 2003).

Para Robbins (2005), a atitude do colaborador em relação ao trabalho realizado representa a satisfação no trabalho. Desta maneira, Spector (2004) descreve a satisfação no trabalho como uma atitude que reflete a reação de uma pessoa em relação ao trabalho de forma geral e em seus vá- rios aspectos. Logo, a satisfação pode ser compreendida como uma variável que reflete o quanto o colaborador gosta do seu trabalho. Para Azevedo e Medeiros (2012), a satisfação trata-se de um estado subjetivo, que pode variar de pessoa para pessoa.

Ainda, segundo Siqueira (2008, p. 259), a satisfação no trabalho, apesar de ultrapassar mais de 80 anos de existência sofrendo mutações em sua concepção (ora compreendida como um aspecto motivacional, ora como atitude e atualmente como um conceito que abrange afetividade), não sofreu maiores alterações em suas dimensões constitutivas, mantendo-se, ao longo das décadas, cinco dimensões: satisfação com o salário, os colegas, a chefia, as promoções e o próprio trabalho; sendo importante conhecer o grau de contentamento dos funcionários com o trabalho, uma vez que fornece indicadores de problemas potenciais e influencia o comportamento.

Além disso, trabalhadores satisfeitos e comprometidos costumam apresentar baixos índices de rotatividade e absenteísmo (Robbins, 2002). Para Koh e Boo (2001 como citado em Penha, Rebouças, Abreu \& Parente, 2016, p. 307) os "gestores devem estar cientes de que reforçar a satisfação no trabalho pode levar a um maior comprometimento organizacional, o que pode levar a um menor absenteísmo e turnover, como também a maior produtividade e lucratividade". Logo, problemas como rotatividade, absenteísmo, estresse, negligencia, saúde (física e mental) comprometida podem prejudicar e provocar a ineficiência do objetivo do Centro de Referência da Assistência Social- CRAS. Com base no exposto, o artigo será guiado pela seguinte problemática: Como a satisfação no trabalho influencia o comprometimento organizacional dos servidores públicos do CRAS de Borborema- PB?

Salienta-se que, segundo o Ministério do Desenvolvimento Social e Combate à Fome (Brasil, 
2009), a mais importante das tecnologias da política de assistência social são os trabalhadores. Ainda afirma que os direitos socioassistenciais dos usuários dos CRAS serão garantidos por meio de profissionais qualificados, comprometidos e devidamente remunerados. Assunção, Domingos, Cabral, Santos e Pessoa (2014) declaram que estudos mostram que os colaboradores satisfeitos tendem a comprometer-se com a organização impactando positivamente no desempenho profissional. Botrel, Mesquita e Bastos (2015), dizem ainda que a satisfação dos servidores e o compromisso organizacional são associados à retenção de funcionários, configurando um importante estímulo para o estudo deste tema, sendo que possuem implicações em vertentes fundamentais para o cumprimento do objetivo da organização.

Por conseguinte, a presente pesquisa almeja analisar a influência da satisfação no trabalho no comprometimento organizacional dos funcionários, haja vista que com estes resultados em mãos o gestor conhecerá aspectos antes desconhecidos, poderá promover subsídios para a tomada de decisões e formulações de estratégias para o desenvolvimento de processos que visem à eficácia do objetivo organizacional.

\section{Referencial teórico}

\subsection{Conceitos e reflexões da satisfação no trabalho}

Apesar de alterações quanto ao conceito ao longo dos séculos, a satisfação no trabalho em diversos estudos tem relação com variáveis importantes à organização. Davis e Newstrom (2004) e Spector (2003) concordam que a satisfação pode ser medida pelo desempenho. Para Robbins (2002), quanto mais satisfeito o colaborador com o trabalho, maior será o envolvimento e o empenho em suas atividades e Spector (2003) relata que a falta de satisfação pode ser a causa da rotatividade dos funcionários.

Neste sentido, Bion (2004) afirma que a satisfação é capaz de afetar a produtividade, a comunicação, a saúde, dentre outros fatores. Portanto, a satisfação no trabalho tem implicações sobre a eficiência, produtividade, qualidade das relações de trabalho, níveis de absenteísmo, comprometimento organizacional, saúde e bem-estar do colaborador (Azevedo \& Egito, 2012 como citado em Hedler \& Castro, 2015). Sendo assim, é de vital importância conhecer o grau de contentamento dos colaboradores para com seu trabalho.

No que refere a estudos sobre satisfação no trabalho, Siqueira (2008) confirma, com base no acúmulo de pesquisas, que características pessoais dos trabalhadores (sexo, idade, estado civil e nível de escolaridade) e do ambiente físico (ruído, temperatura, iluminação) ou de estrutura das organizações (funcional, matricial ou híbrida) pouco contribuem para explicar variações em níveis de satisfação. Moreira (2003) descreve que vários estudos, em diversos países, mostram que o nível de satisfação se distinguiu quanto a valores individuais. Por outro lado, Spector (2003) expressa que alguns estudos apontam que colaboradores mais velhos estariam mais satisfeitos com o trabalho do que os mais jovens. Neste seguimento, Robbins (1999 como citado em Moreira, 2003), considera que o estado civil dos funcionários tem implicações na satisfação. O autor diz que provavelmente isso ocorre devido ao fato do casamento necessitar de mais responsabilidades, tornando o trabalho vital para a vida.

Em relação aos instrumentos para mensuração da satisfação no trabalho, há uma diversificação entre os instrumentos aplicados. Leal, Costa, Cabral, Santos e Pessoa (2015) utilizaram um questionário baseado na satisfação quanto às necessidades humanas básicas, quanto aos fatores higiênicos e quanto aos fatores motivacionais, 
como o usado por Brandão, Lima, Cabral, Santos e Pessoa (2014), mas Assunção et al. (2014) aplicaram um questionário com base apenas nos dois fatores de Herzberg estruturado a partir do questionário desenvolvido por Silva em 2001.

Moreira (2003) utilizou o questionário de satisfação no trabalho contendo 19 facetas do trabalho; Ladeira, Sonza e Berte (2012) optaram por uma modelagem criada por Wright e Davis em 2003; Rosa e Carlotto (2005) escolheram uma versão reduzida do questionário S4/82, o questionário de satisfação no trabalho (s20/23), que avalia a satisfação por cinco dimensões: satisfação com supervisão, com ambiente físico de trabalho, com benefícios e políticas da organização, satisfação intrínseca do trabalho e com a participação.

Já Almeida, Lopes, Costa, Santos e Corrêa (2016), Azevedo e Medeiros (2012), Bonjim, Stefano e Andrade (2010), Garrido (2009), Hedler e Castro (2015), Lima (2013), Martins (2010), Rueda, Santos e Lima (2012), Santos (2008), Santos (2011), Schröder (2012), Tonetto (2013), Wu e Melo (2016), realizaram a pesquisa com a Escala de Satisfação no Trabalho- EST, a maioria aplicada com servidores públicos, obtendo como resultado um consenso entre os servidores, nesses artigos pesquisados, para insatisfação com o salário e com promoções, satisfação com os colegas e com a chefia, e variações entre satisfação e indiferença para a natureza do trabalho.

Diante do exposto, optou-se para esta pesquisa pela abordagem multidimensional, tendo em vista que a mesma oferece um maior embasamento das especificidades da satisfação no trabalho. As dimensões abordadas nesta pesquisa serão as cinco dimensões propostas por Siqueira (2008): satisfação com o salário, com os colegas de trabalho, com a chefia, com as promoções e com o próprio trabalho. O Quadro 1 apresenta o modelo conceitual de Siqueira (2008) adotado nesta pesquisa:

\begin{tabular}{|c|c|}
\hline Dimensões & Descrição \\
\hline $\begin{array}{c}\text { Satisfação com } \\
\text { os colegas }\end{array}$ & $\begin{array}{c}\text { Contentamento com a } \\
\text { colaboração, a amizade, a } \\
\text { confiança e o relacionamento } \\
\text { mantido com os colegas de } \\
\text { trabalho. }\end{array}$ \\
\hline $\begin{array}{c}\text { Satisfação com } \\
\text { o salário }\end{array}$ & $\begin{array}{l}\text { Contentamento com o que recebe } \\
\text { como salário se comparado com o } \\
\text { quanto o indivíduo trabalha, com } \\
\text { sua capacidade profissional, com } \\
\text { o custo de vida e com os esforços } \\
\text { feitos na realização do trabalho. }\end{array}$ \\
\hline $\begin{array}{c}\text { Satisfação com } \\
\text { a chefia }\end{array}$ & $\begin{array}{c}\text { Contentamento com a organização } \\
\text { e capacidade profissional do chefe, } \\
\text { com o seu interesse pelo trabalho } \\
\text { dos subordinados e entendimento } \\
\text { entre eles. }\end{array}$ \\
\hline $\begin{array}{c}\text { Satisfação com } \\
\text { a natureza do } \\
\text { trabalho }\end{array}$ & $\begin{array}{c}\text { Contentamento com o interesse } \\
\text { despertado pelas tarefas, com a } \\
\text { capacidade de elas absorverem o } \\
\text { trabalhador e com a variedade das } \\
\text { mesmas. }\end{array}$ \\
\hline $\begin{array}{l}\text { Satisfação com } \\
\text { as promoções }\end{array}$ & $\begin{array}{c}\text { Contentamento com o número de } \\
\text { vezes que já recebeu promoções, } \\
\text { com as garantias oferecidas a } \\
\text { quem é promovido, com a maneira } \\
\text { da empresa realizar promoções } \\
\text { e com o tempo de espera pela } \\
\text { promoção. }\end{array}$ \\
\hline
\end{tabular}

Quadro 1: Modelo conceitual das dimensōes FONTE: Siqueira (2008, p. 261).

Diante das descrições do Quadro 1 acima, entende-se que o estudo da satisfação no trabalho por meio destas dimensões fornece maiores detalhes de aspectos relacionados ao convívio do colaborador na organização. Para a autora, a satisfação no trabalho "representa a totalização do quanto o indivíduo que trabalha vivencia experiências prazerosas no contexto das organizações" (Siqueira, 2008, p. 259). A autora ainda diz que cada uma das dimensões se refere a um foco, raiz destas experiências prazerosas, logo, podem ofertar informações fundamentais que possam nortear a gestão de pessoas, pois assim, os gestores conhecerão em quais aspectos os funcionários sentem-se mais satisfeitos. 


\subsection{Definição e estudos do comprometimento organizacional}

O comprometimento organizacional pode ser configurado como o laço psicológico que representa a conexão dos indivíduos à organização, e que tem implicações para a decisão de permanência na mesma (Meyer \& Allen, 1991, 1996, Meyer, 1997 como citado em Rego \& Souto, (2004a). Assim, o comprometimento organizacional está relacionado ao vínculo do colaborador com a organização, estando associado ao desejo de permanecer no emprego.

Os estudos sobre o tema se intensificaram a partir do final da década de 1970, tornando um tema bastante pesquisado nas décadas seguintes (Botelho \& Paiva, 2011). Os autores relatam que as pesquisas são marcadas pela variedade de definições e modelos teóricos, resultando numa fragmentação e repetição conceitual.

Nesse contexto, Rego e Souto (2004b) dizem que o interesse no tema é devido a diversas atitudes e comportamentos relevantes que derivam do comprometimento organizacional, como assiduidade, intenção de abandonar a organização, abandono efetivo, pontualidade, atitudes em face da mudança, desempenho individual, comporta- mentos de cidadania, comportamentos de negligência e desempenho organizacional.

Por meio de estudos que comparavam as vertentes afetivas e de continuação, Siqueira (2008) relata que Meyer e Allen encontraram evidências de um modelo bidimensional de comprometimento. Posteriormente, Siqueira (2002) afirma que Meyer, Allen e Smith em 1993 apresentaram um modelo tridimensional de comprometimento organizacional referente às bases afetiva, instrumental e normativo. Os autores construíram três medidas para avaliar separadamente este modelo, sendo estas escalas nomeadas de: Affective Commitemnet Scale (ACS), Calculative Commitemnet Scale (CCS) e Commitemnet Scale Normative (NCS) (Guimarães, 2007). A referida pesquisa abordará as três bases do comprometimento organizacional: afetivo, calculativo ou instrumental e normativo, tendo em vista que, conforme Rego e Souto (2004a), embora a identificação de vários modelos, os mais generalizados são estes três (Quadro 2).

De acordo com as considerações apresentadas no Quadro 2, compreende-se que o estudo do comprometimento mediante essas bases, pode-se

\begin{tabular}{|c|c|c|c|}
\hline Bases & Caracterização & $\begin{array}{c}\text { O colaborador permanece } \\
\text { na organização porque... }\end{array}$ & $\begin{array}{l}\text { Estado } \\
\text { psicológico }\end{array}$ \\
\hline Afetiva & $\begin{array}{c}\text { Grau em que o colaborador se sente } \\
\text { emocionalmente ligado, identificado e } \\
\text { envolvido na organização. }\end{array}$ & $\begin{array}{l}\text {... sente que quer } \\
\text { permanecer. }\end{array}$ & Desejo \\
\hline $\begin{array}{l}\text { Instrumental ou } \\
\text { calculativa }\end{array}$ & $\begin{array}{c}\text { Grau em que o colaborador se mantém } \\
\text { ligado à organização devido ao } \\
\text { reconhecimento dos custos associados com } \\
\text { sua saída da mesma. Este reconhecimento } \\
\text { pode advir da ausência de alternativas } \\
\text { de emprego, ou do sentimento de que os } \\
\text { sacrifícios pessoais gerados pela saída serão } \\
\text { elevados. }\end{array}$ & $\begin{array}{l}\text {... sente que tem } \\
\text { necessidade de } \\
\text { permanecer. }\end{array}$ & Necessidade \\
\hline Normativa & $\begin{array}{c}\text { Grau em que o colaborador possui um } \\
\text { sentido da obrigação (ou do dever moral) de } \\
\text { permanecer na organização. }\end{array}$ & $\begin{array}{l}\text {... sente que deve } \\
\text { permanecer. }\end{array}$ & Obrigação \\
\hline
\end{tabular}

Quadro 2: Três componentes mais comuns do comprometimento organizacional FONTE: Rego (2003, p. 27). 
obter resultados que identificarão o vínculo entre os colaboradores e a organização.

Em relação aos instrumentos, em muitos artigos foi identificada a utilização de instrumentos para medição dessas três dimensões: Peixoto, Bastos, Soares e Lobo (2015) objetivando mensurar o comprometimento organizacional afetivo e normativo; Paulino, Vasconcelos, Alves, Torres, e Lima (2013) para medir o comprometimento organizacional afetivo, instrumental e normativo usaram a escala de comprometimento organizacional elaborada por Rego e Souto; Flaviano, Löbler e Avelino (2014), Gouveia, Milfont, Fischer e Coelho (2009), Maciel e Camargo (2011), Souza, Reche e Sachuk (2013) e Xavier (2005) preferiram as escalas de comprometimento organizacional de Meyer, Allen e Smith no ano de 1991 validadas para o contexto brasileiro de Medeiros e Enders em 1998.

Bastos e Menezes (2010), com o objetivo de medir o comprometimento afetivo, mesclaram alguns itens das escalas: Organizational Commitment Questionnaire (OCQ), de Mowday et al. em 1982, adaptada para o contexto nacional por Borges-Andrade, Afanasieff e Silva (1989) e da Affective Commitment Scale (ACS), de Meyer, Allen e Smith em 1993, adaptada para o país em 1998 por Medeiros e Enders. Müller, Rauski, Eyng e Moreira (2005) aplicaram questionários compostos pela OCQ de Mowday et al., adaptado por Borges-Andrade, Afanasieff e Silva (1989), e pelo instrumento de Meyer Allen e Smith.

Botelho e Paiva (2011), Demo, Martins e Roure (2013), Freitas (2014), Guimarães (2007), Oliveira (2006), Traldi e Demo (2012), escolheram as escalas: ECOA, ECOC e ECON baseadas nos trabalhos de Meyer e Allen de autoria de Siqueira, sendo também utilizada nesta pesquisa, devido aos índices de confiabilidade. Nestas pesquisas, os resultados conduziram a um maior vín- culo afetivo, seguido em algumas do normativo e em outras do calculativo.

No que se refere aos antecedentes do comprometimento organizacional afetivo podem ser consideradas características pessoais e organizacionais, percepção de suporte organizacional e de cultura organizacional, porém, melhor desempenho, menor rotatividade e outros, seriam os aspectos consequentes (Siqueira \& Gomide, 2014). Semelhantemente, Mathieu e Zajac (1990 como citado em Oliveira, 2006) na condução de uma meta-análise no exterior, com 132 amostras com enfoque afetivo, identificaram antecedentes relativos às características pessoais como: a maiores idades, valores éticos e percepção do indivíduo quanto à competência pessoal.

Siqueira e Gomide (2014) consideram fatores como inexistência de ofertas atrativas de novo emprego, tempo de trabalho na empresa, esforços investidos no trabalho e vantagens econômicas no atual emprego como antecedentes do comprometimento calculativo. Os autores dizem que os consequentes deste comprometimento seriam baixa motivação e baixo desempenho, ou seja, aspectos prejudiciais para a organização. Os antecedentes do comprometimento normativo seriam fatores associados à socialização cultural e organizacional, relativo aos consequentes para a organização seriam benéficos como maior satisfação, menor intenção de sair, dentre outros.

Diante destas considerações e consoante Freitas (2014), o entendimento dos aspectos do comprometimento organizacional é importante para o desenvolvimento das relações de trabalho em qualquer setor organizacional, logo, presumese a importância de se compreender o comprometimento que o capital intelectual da organização possui, porque assim, podem-se obter informações para uma melhor gestão. 


\subsection{Correlatos entre satisfação no trabalho e comprometimento organizacional}

É notável, nos artigos pesquisados, a constatação de possíveis relações entre satisfação no trabalho e comprometimento organizacional. Assim, Wu e Melo (2016) dizem, com base em estudos, que a satisfação no trabalho influencia o bem-estar no trabalho, o envolvimento com o trabalho e o comprometimento organizacional. Neste sentido, Schermerhorn, Hunt e Osborn (1999, p.93) citados por Bion (2004), declaram que a satisfação está fortemente relacionada com o comprometimento organizacional e envolvimento no trabalho. Bastos (1993) relata que foram observadas altas correlações entre comprometimento, satisfação e motivação.

Em estudos anteriores, apesar de abordarem também outra variável, demonstrou-se a confirmação da relação positiva entre a satisfação no trabalho e o comprometimento organizacional (Aydogdu \& Asikgil, 2011; Bem-Bakr et al., 1994; Baotham, Hongkhuntod \& Rattanajun, 2010; Shore \& Martin, 1989; Supeli \& Creed, 2015; Yucel, 2012). Destaca-se, por meio de uma pesquisa numa instituição de ensino superior, que Cappi e Araujo (2015) identificaram um padrão de relações positivas e altamente significantes entre a satisfação no trabalho e o comprometimento organizacional.

A partir da análise dos resultados, Lima (2013) identificou algumas correlações significativas entre satisfação no trabalho e comprometimento organizacional. Ainda diz que pesquisas têm divulgado que colaboradores satisfeitos estão propensos a manter-se mais envolvimento com o trabalho e a comprometer-se com a organização empregadora.

Em uma sumarização realizada por Meyer et al. (2002), a satisfação no trabalho apresenta-se como um dos correlatos do comprometimento organizacional segundo a abordagem tridimensional desenvolvida por Meyer e Allen (Paulino, Moura,
Vasconcelos, Alves, \& Torres, 2012). Além disso, os estudos de Meyer et al. (2002) resultaram em uma relação maior entre a satisfação no trabalho e a base afetiva do comprometimento organizacional $(\mathrm{r}=0,650 ; P<0,1)$ do que com as bases normativa $(\mathrm{r}=0,310 ; P<0,1)$ e uma correlação quase nula com o comprometimento organizacional de continuação $(\mathrm{r}=-0,070 ; P<0,1)$ (Souza, Reche, \& Sachuk, 2013).

No estudo em um hospital privado de pequeno porte, Souza, Reche \& Sachuk (2013) concluíram que a satisfação correlacionou mais fortemente com o comprometimento normativo. Assunção et al. (2014) identificaram níveis moderados de correlação positiva entre a satisfação e o comprometimento organizacional afetivo. Já o estudo de Maciel e Camargo (2011), em oito organizações do setor de serviço, revelou que a satisfação no trabalho é preditora significativa da variação das três dimensões do comprometimento, sendo a maior influência sobre as dimensões afetiva e moral.

Numa pesquisa para a identificação da relação entre satisfação e comprometimento com 305 associados de quatro cooperativas agrícolas do estado do Rio Grande do Sul, Flaviano, Löbler e Avelino (2014) observaram que a maior correlação $(0,668)$ está entre as bases do comprometimento (afetivo) e da satisfação. Botrel, Mesquita e Bastos (2015) realizaram um estudo com 309 médicos de instituições hospitalares de Minas Gerais, os resultados identificaram uma influência significativa (valor- $\mathrm{p}=0,00)$ e positiva $(\beta=0,770[0,72$; $0,82])$ da satisfação sobre o comprometimento. Concluindo que, quanto maior a satisfação, maior o comprometimento dos indivíduos.

\section{Procedimentos metodológicos}

Seguindo a classificação de Vergara (2016) esta pesquisa se configura como descritiva e se 
enquadra como estudo de caso, bem como caracteriza uma pesquisa/ levantamento bibliográfico.

Com o intuito de melhor adequar-se aos objetivos, a abordagem utilizada é a quantitativa, segundo Michel (2009), a pesquisa quantitativa usa a quantificação tanto para a coleta de informações como em seus tratamentos, através de técnicas estatísticas.

Com relação ao ambiente de pesquisa temse o CRAS de Borborema- PB, incluindo serviços ofertados como o Programa de Atenção Integral a Família (PAIF) e o Serviço de Convivência e Fortalecimento de Vínculos (SCFV), optou-se por procedimentos de amostragem não probabilista, já que todos os servidores situados nestes serviços se caracterizam como sujeitos da pesquisa.

Afim de melhor adequar-se aos objetivos, esta pesquisa faz uso das escalas: Escala de Satisfação no Trabalho- EST e Comprometimento Organizacional Afetivo- ECOA, Comprometimento Organizacional CalculativoECOC e Comprometimento Organizacional Normativo- ECON, todas as escalas de autoria de Siqueira (2008). Com intuito de mensurar o grau de contentamento no trabalho dos servidores, escolheu uma medida multidimensional a EST na versão reduzida, composta por 15 itens distribuídos em 5 dimensões, com índices de confiabilidade variando de 0,77 a 090.

Para identificar os níveis de comprometimento organizacional, faz-se uso das três bases do comprometimento conceituadas por Meyer e Allen, adaptadas por Siqueira para o contexto brasileiro, são elas: a ECOA é uma medida unidimensional, com índices de confiabilidade 0,93, constituída com 5 itens; a ECOC é uma medida multidimensional com 15 itens, contendo índices de precisão alfas $>0,70$ e a ECON que é uma medida unidimensional formada por 7 itens, com índices de confiabilidade 0,86 .
A presente pesquisa, com base em estudos anteriores e seus possíveis resultados, discorre das seguintes hipóteses a serem testadas:

H1: A satisfação do colaborador no trabalho se correlaciona positivamente com o comprometimento organizacional afetivo;

H2: A satisfação do colaborador no trabalho se correlaciona positivamente com o comprometimento organizacional calculativo;

H3: A satisfação do colaborador no trabalho se correlaciona positivamente com o comprometimento organizacional normativo.

Dessa forma, a fim de melhor atender aos requisitos dos objetivos, foi necessário realizar a análise descritiva dos dados (média, desviopadrão, dentre outros) e posteriormente, o teste de correlação. Para tanto, os dados foram tabulados na planilha do Microsoft Office Excel e analisados com o Statistical Package for the Social Sciences (SPSS) na versão 20.0, um dos softwares mais utilizados para análises estatísticas (Bruni, 2012).

\section{Análise dos dados}

A referida pesquisa se deu no CRAS de Borborema- PB, atingindo os programas vinculados como o PAIF, o Programa Bolsa Família e o SCFV. O CRAS se localiza no Conjunto Nova Esperança, na Rua Paulo dos Santos. Neste prédio, são ofertados o PAIF e o Programa Bolsa Família, um sendo um programa de acompanhamento sociofamiliar, o outro um programa de transferência de renda, respectivamente. O SCFV funciona em outro prédio, que fica na Rua Arthur Thinoco. Suas ações envolvem prevenção de situações de risco social e complementar às atividades sociais com as famílias. 
Consequentemente, com os questionários preenchidos iniciou-se a tabulação dos dados, utilizando as tabelas do Microsoft Excel para a caracterização do perfil dos servidores, usando a tabela dinâmica para a contagem automática dos dados inseridos. Assim, a fim de contribuir para a melhor compreensão do ambiente da pesquisa e captar de forma mais clara o ponto de vista dos servidores em relação à satisfação no trabalho e comprometimento organizacional, foi abordado o perfil dos servidores.

Em relação ao gênero, percebeu-se uma desigualdade, observando que $64 \%$ dos servidores são do sexo feminino, enquanto $36 \%$ declaram ser do sexo masculino, esses valores mostram a forte presença do gênero feminino no âmbito organizacional.

No que se refere à faixa etária, os resultados apontam a maturidade dos colaboradores desta organização, tendo em vista que cerca de $32 \%$ dos servidores possuem acima de 41 anos, seguido de $27 \%$ para servidores acima de 29 até 33 anos, $18 \%$ representa os servidores de até 25 anos, já os que possuem acima de 25 até 29 anos são 14\% e para os servidores que possuem acima de 33 anos até 37 anos e acima de 37 até 41 anos são apenas $4,5 \%$, cada.

Quanto ao estado civil, 68\% dos colaboradores são casados ou possuem união estável e $32 \%$ são solteiros, deste modo, entende-se que maioria dos servidores possui obrigação/ responsabilidades para com a família e necessita do emprego. Em referência ao quadro funcional, $23 \%$ são facilitadores/ oficineiros; auxiliares de serviços gerais e agentes administrativos, ambos representam 18\%; 9\% são da coordenação; para assistente social, brinquedoteca, conselheiro tutelar, operador do Bolsa Família, orientador, profissional de Educação Física e psicólogo, cada um representa $4,5 \%$.
No que diz respeito ao tempo de serviço na empresa atual, $45 \%$ têm acima de 1 ano e 6 meses, $36 \%$ para os que tem até 6 meses, acima de 6 meses até 1 ano e acima de 1 ano até 1 ano e 6 meses, ambos representam 9\% dos servidores. Logo, pode-se inferir que grande parte dos servidores possui certos laços com a organização pelo fato destes terem mais de 1 ano neste ambiente.

Sobre o grau de escolaridade, a maior parte dos colaboradores possui curso superior completo/ incompleto $(59,5 \%), 36 \%$ ensino médio completo/ incompleto e $4,5 \%$ ensino fundamental completo/ incompleto.

Os demais tópicos tratam da análise dos resultados coletados por meio das escalas, que foram explicitados nas tabelas contendo a média, considerada o ponto de equilíbrio das frequências e o desvio padrão das variáveis, que indica a dispersão existente em relação à média, sendo assim, um baixo desvio padrão indica que os valores tendem a se aproximar da média e um desvio padrão alto, que os dados estão dispersos por uma sucessão de valores. A seguir, foram apresentados os resultados alcançados referentes ao grau de satisfação no trabalho e suas dimensões.

\subsection{Grau de satisfação no trabalho e suas dimensões}

Neste tópico, na Tabela 1, foram apresentados os resultados obtidos com a escala de satisfação no trabalho, Siqueira (2008) destaca que na interpretação dos resultados quanto maior for o valor da média, maior será o grau de contentamento do funcionário com a dimensão, assim, valores entre 5 e 7 tendem a indicar satisfação, os valores entre 1 e 3,9 sinalizam insatisfação, enquanto valores entre 4 e 4,9 apontam estado de indiferença.

$\mathrm{Na}$ observação dos resultados por dimensões, as médias oscilam de 4,0 (indiferença) a 5,7 (satisfação) e os desvios de 0,65 a 1,44, nota-se que os servidores estão satisfeitos com os colegas, 
Tabela 1: Média e desvio-padrão da Escala de Satisfação no Trabalho

\begin{tabular}{|c|c|c|c|}
\hline Dimensões & Afirmativas & Média & Desvio \\
\hline \multirow{3}{*}{$\begin{array}{c}\text { Satisfação com os } \\
\text { colegas }\end{array}$} & $\begin{array}{l}\text { Com o espírito de colaboração } \\
\text { dos meus colegas de trabalho. }\end{array}$ & 5,7 & 0,86 \\
\hline & $\begin{array}{l}\text { Com o tipo de amizade que } \\
\text { meus colegas demonstram por } \\
\text { mim. }\end{array}$ & 5,5 & 0,85 \\
\hline & $\begin{array}{c}\text { Com a confiança que eu } \\
\text { posso ter em meus colegas de } \\
\text { trabalho. }\end{array}$ & 5,3 & 0,90 \\
\hline \multirow{3}{*}{$\begin{array}{l}\text { Satisfação com o } \\
\text { salário }\end{array}$} & $\begin{array}{c}\text { Com o meu salário comparado } \\
\text { com o quanto eu trabalho. }\end{array}$ & 4,4 & 0,85 \\
\hline & $\begin{array}{c}\text { Com o meu salário comparado } \\
\text { à minha capacidade } \\
\text { profissional. }\end{array}$ & 4,2 & 1,16 \\
\hline & $\begin{array}{l}\text { Com meu salário comparado } \\
\text { aos meus esforços no trabalho. }\end{array}$ & 4,7 & 1,03 \\
\hline \multirow{3}{*}{$\begin{array}{l}\text { Satisfação com a } \\
\text { chefia }\end{array}$} & $\begin{array}{c}\text { Com o entendimento entre eu e } \\
\text { meu chefe. }\end{array}$ & 5,3 & 0,71 \\
\hline & $\begin{array}{l}\text { Com a maneira como meu } \\
\text { chefe me trata. }\end{array}$ & 5,2 & 0,86 \\
\hline & $\begin{array}{c}\text { Com a capacidade profissional } \\
\text { do meu chefe. }\end{array}$ & 5,2 & 0,82 \\
\hline \multirow{3}{*}{$\begin{array}{l}\text { Satisfação com } \\
\text { a natureza do } \\
\text { trabalho }\end{array}$} & $\begin{array}{l}\text { Com o grau de interesse que } \\
\text { minhas tarefas me despertam. }\end{array}$ & 5,1 & 1,24 \\
\hline & $\begin{array}{l}\text { Com a capacidade de meu } \\
\text { trabalho absorver-me. }\end{array}$ & 5,0 & 0,65 \\
\hline & $\begin{array}{c}\text { Com a variedade de tarefas } \\
\text { que realizo. }\end{array}$ & 5,3 & 0,83 \\
\hline \multirow{3}{*}{$\begin{array}{l}\text { Satisfação com as } \\
\text { promoções }\end{array}$} & $\begin{array}{l}\text { Com o número de vezes que já } \\
\text { fui promovido nesta empresa. }\end{array}$ & 4,2 & 1,44 \\
\hline & $\begin{array}{l}\text { Com a maneira como esta } \\
\text { empresa realiza promoções de } \\
\text { seu pessoal. }\end{array}$ & 4,2 & 1,06 \\
\hline & $\begin{array}{l}\text { Com as oportunidades de ser } \\
\text { promovido nesta empresa. }\end{array}$ & 4,0 & 0,95 \\
\hline TOTAL GERAL & & 4,8 & 0,94 \\
\hline
\end{tabular}

Fonte: Dados da pesquisa (2017).

destacando a afirmativa "com o espírito de colaboração dos meus colegas de trabalho" com média $(5,7)$, entendendo que os servidores possuem bons relacionamentos na organização. Para Davis e Newstrom (2004), quando existe cooperação e trabalho em equipe, as pessoas encontram maior satisfação no trabalho.

A respeito da satisfação com a chefia, a segunda maior média entre as dimensões, os servidores se mostram satisfeitos com o líder, ressaltando valores próximos, com maior média das afirmativas o "entendimento entre o chefe e o respondente" $(5,3)$, que indica um bom entendimento e relacionamento entre os subordinados e a chefia. Conforme Siqueira (2008), em diversos resultados de pesquisas, a satisfação no trabalho é sensível às práticas gerenciais, ou seja, certa divergência entre os subordinados e seu líder pode, dentre outros fatores, ter influência no nível de satisfação do indivíduo para com o trabalho.

Os servidores também apresentaram satisfação com a natureza do trabalho, isso indica que os colaboradores possuem certo interesse pelas atividades que desenvolvem na instituição. A maior média dessa dimensão foi 5,3 ; referente à variedade de atividades que realiza, a maioria dos funcionados se satisfaz com trabalhos interessantes que promovam treinamento, variedade, dentre outros fatores (Robbins, 2005). Destacando a afirmativa "capacidade de meu trabalho absorverme", que obteve o menor desvio entre as demais $(0,65)$, apontando aproximação das respostas, podendo atribuir esta aproximação ao fato das atividades envolverem prestação de serviços sociais, que necessitam de atenção e dedicação às atividades e ao próximo.

Em relação à satisfação como salário e às promoções, os servidores se apresentam indiferentes, ou seja, nem satisfeitos, nem insatisfeitos. No que se refere aos salários, a menor média $(4,2)$ simboliza o salário comparado à capacidade profissional, fato coerente, tendo em vista que a maioria possui nível superior completo ou incompleto e, 
em contrapartida, o quadro funcional é composto majoritariamente por facilitador, auxiliar de serviços gerais e agentes administrativos. Logo, a satisfação com salário não é determinada pela quantia em si, mas pela justiça ou equidade de como é feita a distribuição (Arruda \& Rodriguez, 2012).

Quanto às promoções, a menor média $(4,0)$ representa as oportunidades de ser promovido. Infere-se que esse resultado tenha a ver com o fato do ingresso ou do avanço de cargo efetivo no serviço público se dê por meio do concurso público, conclusão semelhante ao de Hedler e Castro (2015) para a insatisfação dos servidores do CRAS do Paranavaí para as promoções. O maior desvio se localiza nesta dimensão, para a afirmativa "número de vezes que já fui promovido" $(1,44)$, significando disseminação de respostas para a afirmativa, podendo ser atribuído ao fato da organização não utilizar plano de carreira, cargos e salários dificultando a ocorrência de promoções.

Os resultados relativos às dimensões obtiveram alguns resultados semelhantes aos artigos consultados, em que a maioria dos servidores estaria satisfeito com os colegas e com a chefia, e com as variações entre satisfação e indiferença para a natureza do trabalho, porém nestes estudos os funcionários apresentam insatisfação com o salário e as promoções (Almeida et al., 2016; Azevedo \& Medeiros, 2012; Bonjim, Stefano, \& Andrade 2010; Garrido, 2009; Hedler \& Castro, 2015; Lima, 2013; Martins, 2010; Rueda, Santos, \& Lima, 2012; Santos, 2008; Santos, 2011; Schröder, 2012; Tonetto, 2013; Wu \& Melo, 2016).

Essas poucas diferenças entre os resultados encontrados nesta pesquisa e os coletados em outros estudos mostram que o estudo das dimensões é algo dinâmico, que pode variar de caso em caso e de organização para organização, mesmo que estas sejam do setor público, confirmando, assim, o que Siqueira e Gomide (2014) falam que há dife- renças entre as dimensões e que podem variar de situação para situação.

Com relação à satisfação geral, a partir da média $(4,8)$ e do desvio padrão $(0,94)$, esses revelam que apesar dos servidores estarem satisfeitos com os colegas, com a chefia e com a natureza do trabalho, os servidores encontram-se indiferentes, não apresentado insatisfação e nem satisfação, porém devido à aproximação da média ao valor 5 , observa-se uma inclinação dos servidores a estarem satisfeitos, resultado semelhante ao estudo de Garrido (2009) com servidores do Superior Tribunal de Justiça, que indicou que a satisfação dos servidores com o trabalho, no geral, variava de indiferentes a satisfeitos com o trabalho.

Diante deste resultado, Schröder (2012) associa um alto nível de satisfação no trabalho a atitudes positivas em relação a ele, enquanto a não satisfação no trabalho apresenta atitudes negativas, sendo prejudicial ao ambiente de trabalho, deste modo, entende-se que os servidores do CRAS de Borborema podem apresentar ou apresentam ações positivas na instituição. Porém, como identificado nesses resultados, nota-se uma proximidade com a afirmativa de Bonfim, Stefano e Andrade (2010), embora os servidores possam apresentar satisfeitos de forma geral com seu trabalho, não necessariamente significa que estejam contentes com todos seus aspectos/ dimensões.

Em sequência, serão apresentadas as análises relacionadas ao comprometimento organizacional e a identificação do comprometimento organizacional predominante na organização.

\subsection{Comprometimento organizacional e suas bases}

Levando em consideração que a identificação do comprometimento organizacional pode ser uma grande aliada à instituição, neste sentido, Rego (2003, p. 27) afirma que "a vontade dos indivíduos de contribuírem para os objetivos organi- 
zacionais parece ser influenciada pela natureza do laço psicológico que os liga à organização”.

A Tabela 2 exibe os resultados obtidos na Escala de Comprometimento Organizacional Afetivo- ECOA. Siqueira (2008) sugere que quanto maior o valor médio, mais forte é o compromisso afetivo com a organização, deste modo, empregados afetivamente comprometidos sinalizam valores entre 4 e 5, os empregados que apresentarem valores entre 3 e 3,9 sugerem indecisão quanto ao seu vínculo afetivo, já valores entre 1 e 2,9 podem indicar frágil compromisso afetivo com a organização.

\begin{tabular}{|c|c|c|}
\hline Afirmativas & Média & Desvio \\
\hline Orgulhoso dela & 4,1 & 1,22 \\
\hline Contente com ela & 3,9 & 1,23 \\
\hline Entusiasmado com ela & 4,0 & 1,25 \\
\hline Interessado por ela & 4,1 & 1,28 \\
\hline Animado com ela & 4,0 & 1,25 \\
\hline TOTAL GERAL & 4,0 & 1,24 \\
\hline
\end{tabular}

Fonte: Dados da pesquisa (2017).

De acordo com o apresentado na Tabela 2, observa-se proximidade entre as médias $(3,9$ a $4,1)$ e valores altos para os desvios $(1,22$ a 1,28$)$. Por meio do desvio, nota-se a dispersão de dados. Nesta escala, são observados sentimentos no ambiente de trabalho. $\mathrm{Na}$ maioria das médias, os servidores apresentam estar de acordo com os sentimentos de orgulho, interesse, entusiasmo e animado, ressaltando a indecisão ao sentimento de contente com média 3,9; porém, observa-se uma inclinação destes a se sentirem mais contentes do que menos, inferindo assim, que as atividades sociais desenvolvidas afloram estes sentimentos por se sentirem bem ao ajudar os carentes, semelhante à afirmativa de Mowday et al. (1982 como citado em Guimarães, 2007) em que o vínculo afetivo está associado ao grau de identificação pessoal e de envolvimento com uma organização em particular.
De maneira geral, os servidores possuem vínculos afetivos com a instituição, chegando a esta analise através da média 4,0 e levando em consideração as instruções de Siqueira (2008) que médias entre 4 e 5 sinalizam que o empregado se sente afetivamente comprometido com a organização. Para Rego (2003), o colaborador afetivamente comprometido com a organização se sente emocionalmente ligado, envolvido na organização, ou seja, o colaborador permanece na organização porque quer/ deseja ficar.

Logo, os servidores possuem vínculos afetivos com a instituição, esta ligação possa ter relação os serviços sociais prestados, a sensação de contribuir, de ser importante para o próximo, como Siqueira (2008) descreve o comprometimento afetivo como a identificação do indivíduo com os valores e objetivos organizacionais, implicando em consequentes bons a organização como melhor desempenho, menor rotatividade e outros (Siqueira \& Gomide, 2014).

Dando sequência, abaixo, na Tabela 3, são mostrados os dados obtidos na Escala de Comprometimento Organizacional CalculativoECOC, referente às perdas e dificuldades, caso pedisse demissão e fosse trabalhar em outra organização:

$\mathrm{Na}$ Tabela 3, percebe-se a oscilação de valores, com médias de 1,9 (discordo totalmente) a 3,3 (nem concordo nem discordo) e desvios de 1,10 a 1,55; novamente, uma grande dispersão de valores. Siqueira (2008) informa que se deve realizar a análise particular de cada um dos quatro componentes da escala, considerando o valor obtido e o conteúdo semântico do fator, logo, mediante exemplo da autora para análise, médias entre 4 e 5 em perdas sociais no trabalho representam que o trabalhador acredita que ao deixar a empresa perderia a estabilidade no emprego, o prestígio do cargo, o contato de amizade com os colegas de trabalho e a liberdade de realizar o trabalho. Valores para este com- 
Tabela 3: Escala de Comprometimento Organizacional CalculativoECOC

\begin{tabular}{|c|c|c|c|}
\hline Dimensões & Afirmativas & Média & Desvio \\
\hline \multirow{4}{*}{$\begin{array}{l}\text { Perdas sociais no } \\
\text { trabalho }\end{array}$} & $\begin{array}{c}\text { Eu perderia a estabilidade no } \\
\text { emprego que tenho hoje nesta } \\
\text { empresa (garantias de não ser } \\
\text { demitido). }\end{array}$ & 2,4 & 1,10 \\
\hline & $\begin{array}{l}\text { Eu teria dificuldade para } \\
\text { conseguir outro cargo que me } \\
\text { desse o mesmo prestígio que } \\
\text { tenho com o meu cargo atual. }\end{array}$ & 1,9 & 1,21 \\
\hline & $\begin{array}{l}\text { Eu demoraria a encontrar em } \\
\text { outra empresa pessoas tão } \\
\text { amigas quanto as que eu tenho } \\
\text { hoje entre meus colegas de } \\
\text { trabalho dentro desta empresa. }\end{array}$ & 3,0 & 1,21 \\
\hline & $\begin{array}{c}\text { Eu perderia a liberdade que } \\
\text { tenho de realizar meu trabalho } \\
\text { dentro desta empresa. }\end{array}$ & 2,6 & 1,42 \\
\hline \multirow{3}{*}{$\begin{array}{l}\text { Perdas de } \\
\text { investimentos } \\
\text { feitos na } \\
\text { organização }\end{array}$} & $\begin{array}{l}\text { Eu jogaria fora todos os esforços } \\
\text { que fiz para chegar aonde } \\
\text { cheguei dentro desta empresa. }\end{array}$ & 2,5 & 1,18 \\
\hline & $\begin{array}{c}\text { Eu estaria desperdiçando todo } \\
\text { o tempo que já me dediquei a } \\
\text { esta empresa. }\end{array}$ & 2,5 & 1,28 \\
\hline & $\begin{array}{c}\text { Eu deixaria para trás tudo o que } \\
\text { já investi nesta empresa. }\end{array}$ & 2,2 & 1,27 \\
\hline \multirow{3}{*}{$\begin{array}{l}\text { Perdas de } \\
\text { retribuições } \\
\text { organizacionais }\end{array}$} & $\begin{array}{l}\text { Eu teria dificuldades para } \\
\text { ganhar um salário tão bom } \\
\text { quanto o que tenho hoje. }\end{array}$ & 2,4 & 1,33 \\
\hline & $\begin{array}{l}\text { Eu deixaria de receber vários } \\
\text { benefícios que esta empresa } \\
\text { oferece aos seus empregados } \\
\text { (vale-transporte, convênios } \\
\text { médicos, vale refeição, etc.). }\end{array}$ & 3,3 & 1,55 \\
\hline & $\begin{array}{c}\text { Eu teria mais coisas a perder do } \\
\text { que a ganhar com este pedido } \\
\text { de demissão. }\end{array}$ & 2,9 & 1,46 \\
\hline \multirow{5}{*}{$\begin{array}{l}\text { Perdas } \\
\text { Profissionais }\end{array}$} & $\begin{array}{l}\text { Eu estaria prejudicando minha } \\
\text { vida profissional. }\end{array}$ & 2,2 & 1,10 \\
\hline & $\begin{array}{c}\text { Eu demoraria a conseguir } \\
\text { ser tão respeitado em outra } \\
\text { empresa como sou hoje dentro } \\
\text { desta empresa. }\end{array}$ & 2,1 & 1,12 \\
\hline & $\begin{array}{c}\text { Eu perderia o prestígio que } \\
\text { tenho hoje por ser empregado } \\
\text { desta empresa. }\end{array}$ & 2,1 & 1,15 \\
\hline & $\begin{array}{l}\text { Eu levaria muito tempo para me } \\
\text { acostumar a um novo trabalho. }\end{array}$ & 2,5 & 1,29 \\
\hline & $\begin{array}{l}\text { Eu estaria jogando fora todo o } \\
\text { esforço que fiz para aprender } \\
\text { as tarefas do meu cargo atual. }\end{array}$ & 2,1 & 1,13 \\
\hline TOTAL GERAL & & 2,4 & 1,25 \\
\hline
\end{tabular}

Fonte: Dados da pesquisa (2017).

ponente entre 1 e 2 indicam que o funcionário não acredita que teria essas perdas; médias entre 3 e 3,9 apontam incerteza do trabalhador sobre a possibilidade de vir a ter perdas sociais no trabalho, caso peça demissão.

Avaliando cada aspecto, todos os valores indicam que os servidores discordam com as perdas e as maiores médias estão ligadas às perdas de retribuições organizacionais, sinalizando que os servidores não acreditam que teriam essas dificuldades, com destaque à dúvida sobre os benefícios ofertados pela empresa, com média 3,3 e desvio 1,55 , ressaltando a heterogeneidade nas respostas. Pode-se associar estes resultados ao fato da organização não propiciar certos benefícios e que a maioria recebe até um salário mínimo, desde modo, os servidores ponderaram os custos e benefícios associados à saída (Oliveira, 2006).

A respeito das perdas sociais no trabalho, os valores sinalizam que os servidores não acreditam que ao deixar a empresa que trabalha poderiam ter essas dificuldades. Com menor média $(1,9)$, "dificuldades em conseguir o prestígio no cargo", podendo estar relacionado ao grau de escolaridade. Os servidores apresentaram dúvida $(3,0)$ quanto ao encontrar amizade com os colegas de trabalho como tem nesta empresa, sinalizando a cumplicidade, o entendimento entre os servidores, que pode representar que o vínculo entre os colaboradores se configura como uma perda a ser ponderada na decisão de permanência. Para Bastos 
e Menezes (2010), as intenções de permanecer na instituição podem ser motivadas também pelos grupos e equipes de trabalho.

Nas perdas de investimentos feitos na organização, os servidores mostram que não perderiam tempo, nem esforço e investimento ao deixar a organização, o que pode ter vínculo com as atividades exercidas, pois por se tratar de uma organização que presta serviços sociais, grande parte do investimento como tempo e esforço repercutiram positivamente em outra vida, ou seja, pode ter havido uma associação destes investimentos, por parte dos servidores, com valores/ princípios morais. Para Oliveira (2006) o balanço avaliativo realizado pelo colaborador pode ser representado, mentalmente, por crenças, percepções ou avaliações com relação à troca.

Quanto às perdas profissionais, os valores revelam que os servidores não encaram a saída da organização como prejuízo a sua vida profissional, tendo em vista que a NOB-RH/SUAS estabelece a viabilização da participação dos colaboradores em capacitação e formação no âmbito das três esferas do governo, portanto, os trabalhadores podem entender que a estadia nesta instituição tenha sido profissionalmente benéfica.

No geral o comprometimento organizacional calculativo é fraco $(2,4)$, indicando que os servidores não permanecem na organização porque necessitam, configurando um bom resultado, dado que Traldi e Demo (2012) afirmam que servidores com forte comprometimento calculativo permanecem na organização enquanto esta for atraente aos mesmos.

Semelhantemente, Rego (2003) associa a permanência do colaborador ao reconhecimento dos custos ligados à saída da organização. Sabendo, por meio de Siqueira e Gomide (2014), que como consequentes deste comprometimento seriam baixa motivação e baixo desempenho, pode-se dizer que este resultado é vantajoso à organização, pois a predominância deste comprometimento poderia acarretar aspectos prejudiciais à organização.

Em continuidade, a Tabela 4 apresenta os dados alcançados a partir da Escala de Comprometimento Organizacional NormativoECON. Siqueira (2008) diz que o valor médio quanto mais próxima de 5 , mais o colaborador acredita em seu compromisso normativo, portanto, médias entre 4 e 5 o trabalhador pode acreditar ter obrigações e deveres morais para com a organização, valores entre 3 e 3,9 podem indicar incerteza do trabalhador quanto ao seu compromisso normativo e valores entre 1 e 2 indicam que o trabalhador não acredita que deva manter obrigações e deveres morais para com a organização.

\begin{tabular}{|c|c|c|}
\hline Afirmativas & Média & Desvio \\
\hline $\begin{array}{l}\text { Continuar trabalhando nesta } \\
\text { empresa é uma forma de } \\
\text { retribuir o que ela já fez por mim. }\end{array}$ & 2,2 & 1,10 \\
\hline $\begin{array}{l}\text { É minha obrigação continuar } \\
\text { trabalhando para esta empresa. }\end{array}$ & 2,1 & 1,12 \\
\hline $\begin{array}{c}\text { Eu seria injusto com esta } \\
\text { empresa se pedisse demissão } \\
\text { agora e fosse trabalhar para } \\
\text { outra. }\end{array}$ & 2,2 & 1,15 \\
\hline $\begin{array}{l}\text { Neste momento esta empresa } \\
\text { precisa dos meus serviços. }\end{array}$ & 2,5 & 1,29 \\
\hline $\begin{array}{c}\text { Seria desonesto de minha parte } \\
\text { ir trabalhar para outra empresa } \\
\text { agora. }\end{array}$ & 2,1 & 1,13 \\
\hline TOTAL GERAL & 2,2 & 1,15 \\
\hline
\end{tabular}

Fonte: Dados da pesquisa (2017).

Novamente, são notadas proximidades para os valores das médias $(2,1$ a 2,5$)$ e desvios altos, que variam de 1,10 a 1,29. Ao analisar, percebese que todas as afirmativas indicam discordância para os servidores. A afirmativa que apresenta mais homogeneidade nas respostas $(1,10)$ com média $(2,2)$ indica que os servidores não acreditam que continuar trabalhando seria uma forma de retribuição. Assim, pode conceber que os colaboradores não permanecem a exercer suas ati- 
vidades sociais apenas por retribuição a alguma dívida ou benefício concedido pela instituição. Para Siqueira (2008), o comprometimento normativo é integrado por crenças do trabalhador sobre a dívida social ou a necessidade de retribuir um favor a organização.

Com relação ao desvio mais disperso $(1,29)$ com média $(2,5)$, indica uma variação nas repostas referentes ao colaborador permanecer na empresa por ela necessitar de seus serviços, representado divergência nos valores dados, podem ter relação ao tipo de serviços, que podem requerer experiência e habilidades destes servidores. A respeito desta afirmativa, Traldi e Demo (2012) dizem que em organizações que apresentam comprometimento normativo, o contato entre os funcionários e a empresa se assemelha a uma família, regras e missões muito fortes, fazendo com que o colaborador tenha crença de que a empresa precisa dele para se desenvolver.

Em referência à média total $(2,2)$ do comprometimento organizacional normativo, revela, segundo Siqueira (2008), que o servidor não acredita que deva manter obrigações e deveres morais para com a organização. Desse modo, os servidores não permanecem por obrigação. Para Rego (2003), funcionários com elevado grau de comprometimento normativo possuem sentimento de obrigação/ dever moral de permanecer na organização.

Assim, entende-se que os servidores do CRAS não apresentam vínculos normativos, ou seja, não permanecem por se sentirem presos a um contrato e/ou uma dívida para com a organização. De acordo com Traldi e Demo (2012), trabalhadores comprometidos normativamente continuam na organização porque possuem sentimento de dívida ou obrigação, estes estabelecem com a organização um contrato psicológico (Paulino et al., 2013).

Em resumo, foi identificado que o comprometimento organizacional predominante nesta instituição é o afetivo $(4,0)$, traços fracos do calculativo $(2,4)$ e do normativo $(2,2)$, similar aos resultados de várias pesquisas que conduziram a um maior vínculo afetivo, seguido em algumas do normativo e em outras do calculativo (Botelho \& Paiva, 2011; Demo, Martins, \& Roure, 2013; Freitas, 2014; Guimarães, 2007; Oliveira, 2006; Traldi \& Demo, 2012).

Conforme Rego e Souto (p. 34, 2004b), colaboradores afetivamente comprometidos apresentam um menor turnover, baixo absenteísmo, desempenho mais elevado e comportamentos superiores de cidadania organizacional. Os autores ainda afirmam que é mais provável que colaboradores apresentem elevados esforços de desempenho quando desejam pertencer à organização, do que quando se sentem obrigados ou necessidade de permanecerem. Logo, os resultados acima são satisfatórios, haja vista que o comprometimento afetivo acarreta benefícios e características importantes para o bom funcionamento das atividades da empresa.

\subsection{Correlação entre a satisfação no trabalho e o comprometimento organizacional}

Em conformidade com o objetivo geral, serão mostrados os resultados atingidos referentes à correlação, que, segundo Bruni (2012), serve para medir o grau de relação entre variáveis, neste caso, a satisfação no trabalho e o comprometimento organizacional afetivo, calculativo e normativo, expostos na Tabela 5.

Os resultados obtidos na correlação de Pearson (Tabela 5) são analisados de acordo com Barbetta (2005 como citado em Lima, 2013): a correlação pode ser positiva ou negativa e variar de fraca a forte. A metodologia utilizada foi a mesma adotada por Lima (2013), considerando correlação fraca (0 a 0,30$)$, correlação moderada 
Tabela 5: Correlação entre a Satisfação no Trabalho e o Comprometimento Organizacional Afetivo, Calculativo e Normativo

\begin{tabular}{c|c|c|c}
\hline $\begin{array}{c}\text { CORRELAÇÃO DE } \\
\text { PEARSON }\end{array}$ & $\begin{array}{c}\text { ECOA } \\
\text { Comprometimento } \\
\text { Organizacional Afetivo }\end{array}$ & $\begin{array}{c}\text { ECOC } \\
\text { Comprometimento } \\
\text { Organizacional } \\
\text { Calculativo }\end{array}$ & $\begin{array}{c}\text { ECON } \\
\text { Comprometimento } \\
\text { Organizacional Normativo }\end{array}$ \\
\hline $\begin{array}{c}\text { SATISFAÇÃO NO } \\
\text { TRABALHO }\end{array}$ & 0,401 & 0,179 & 0,207 \\
\hline
\end{tabular}

Fonte: Dados da pesquisa (2017).

$(0,31$ a 0,65$)$ e correlação forte $(0,66$ a 1$)$. A seguir, são apresentadas as hipóteses e os resultados obtidos na correlação.

H1: A satisfação do colaborador no trabalho se correlaciona positivamente com o comprometimento organizacional afetivo;

Os resultados apontam uma correlação positiva e moderada entre a satisfação do colaborador no trabalho e comprometimento organizacional afetivo $(0,401)$, aceitando assim a H1. Para Van Breugel et al. (2005 como citado em Botrel, Mesquita, \& Bastos, 2015), há a correlação positiva entre comprometimento afetivo e satisfação no trabalho, pois segundo os autores, a satisfação aumenta, no empregado, o sentimento de pertencer à empresa. Percebe-se um resultado próximo aos consultados nas pesquisas, como o estudo de Assunção et al. (2014) que identificou níveis moderados de correlação positiva entre a satisfação no trabalho e o comprometimento organizacional afetivo. Flaviano, Löbler e Avelino (2014) também observaram uma maior correlação entre o comprometimento organizacional afetivo e a satisfação no trabalho.

H2: A satisfação do colaborador no trabalho se correlaciona positivamente com o comprometimento organizacional calculativo;

Com relação à satisfação do colaborador no trabalho e comprometimento organizacional calculativo, nota-se uma correlação positiva e fraca $(0,179)$, aceitando a $\mathbf{H} 2$. Ainda de acordo com Van Breugel et al. (2005 como citado em Botrel, Mesquita, \& Bastos, 2015), a satisfação no trabalho exerce influência no comprometimento calculativo, levando em consideração que o empregado pode avaliar os benefícios que receberia em outro emprego e ao optar, permanecer e se dedicar ao máximo para mantê-los.

Consoante Maciel e Camargo (2011) relatam que a satisfação no trabalho sirva como um dos principais benefícios ponderados ao decidir a permanência na organização, os autores complementam afirmando que o risco de não se sentir bem no novo emprego é pensado na decisão de saída como um custo.

H3: A satisfação do colaborador no trabalho se correlaciona positivamente com o comprometimento organizacional normativo.

Quanto à correlação entre satisfação no trabalho e comprometimento organizacional normativo tem-se um índice positivo e fraco (0,207), sendo aceita a H3. Conforme Van Breugel et al. (2005 como citado em Botrel, Mesquita, \& Bastos, 2015), a satisfação no trabalho se correlaciona positivamente com o comprometimento normativo, afinal, pode impactar na decisão de permanência, pois o colaborador pode se sentir obrigado a permanecer em uma organização que satisfaz suas necessidades (Maciel \& Camargo, 2011). Siqueira e Gomide (2014) associam como 
consequentes deste comprometimento uma maior satisfação no trabalho.

Em resumo, observa-se uma hierarquia em que a satisfação no trabalho se correlaciona positivamente com o comprometimento afetivo $(0,401)$, normativo $(0,207)$ e calculativo $(0,179)$. Similar aos estudos de Meyer et al. (2002 como citado em Souza, Reche \& Sachuk, 2013), que resultaram em uma relação maior entre a satisfação no trabalho e a base afetiva, do que com a base normativa. Resultado equivalente foi obtido no estudo de Maciel e Camargo (2011), revelando que a satisfação no trabalho é preditora das três dimensões do comprometimento, sendo a maior influência sobre as dimensões afetiva e normativa.

No geral, a satisfação no trabalho se correlacionou com as três bases do comprometimento organizacional, indicando que quanto maior a satisfação no trabalho, maior será o comprometimento do servidor.

\section{Considerações finais}

O presente estudo possibilitou uma análise da influência da satisfação no trabalho no comprometimento organizacional dos servidores do CRAS de Borborema, por meio de revisão literária e principalmente das colocações dos servidores. Permitiu a identificação do comprometimento organizacional predominante e o conhecimento do nível de satisfação no trabalho desses servidores.

A respeito do perfil dos servidores, a maioria declara ser do sexo feminino, com faixa etária acima de 41 anos, sendo $68 \%$ casados/união estável, grande parte possui curso superior completo/ incompleto, com tempo de serviço acima de 1 ano e 6 meses, nesta organização o quadro funcional é formado principalmente por facilitadores, auxiliar de serviços gerais e agentes administrativos.
Com relação à satisfação no trabalho, podese constatar que os servidores apresentam indiferentes, mas propensos a estarem satisfeitos. Este estudo possibilitou conhecer a avaliação dos servidores para cada dimensão da satisfação no trabalho, apontando que os servidores apresentam satisfação com os colegas, com a chefia e com a natureza do trabalho, indicando um ambiente agradável de trabalho, com bons relacionamentos interpessoais e identificação com atividades desempenhadas na organização.

Porém, os servidores estão indiferentes ao salário e às promoções, no que se refere ao salário pode ser atribuído ao fato do salário ser um fator higiênico. Quanto às promoções, pode ser associado ao nível de escolaridade e a organização não praticar planos que favoreçam promoções em uma organização pública, sendo necessária, a instituição, reavaliar suas estratégias e táticas para assim consolidar a satisfação no trabalho em todos seus aspectos.

Sobre o comprometimento organizacional, foi possível identificar a base do comprometimento predominante. Nesta instituição, os servidores identificam-se com o comprometimento afetivo, indicando a prevalência da identificação dos colaboradores com os objetivos e valores organizacionais.

A prevalência do vínculo afetivo pode ter recebido influências de alguns aspectos organizacionais como a natureza do trabalho por se tratar de uma organização que atende pessoas socialmente vulneráveis, dos quais os servidores convivem cotidianamente com pessoas sejam crianças, adolescentes, adultos, gestantes, idosos que exprime cuidado e atenção; e pela percepção de suporte organizacional quanto às condições de trabalho, como espaço físico e material como previsto pela NOB-RH/SUAS.

A respeito do valor obtido para o comprometimento calculativo, infere-se que o mesmo não apresentou predominância devido ao nível de in- 
diferença constatado pelos servidores em relação ao salário e às promoções. Compreende-se que a quantia do salário e as promoções podem não ser um motivo forte de permanência nesta instituição, bem como o nível de escolaridade, sugerindo que estes servidores não teriam dificuldades em conseguir emprego; outro fator pode ter relação com a estabilidade, entende-se que a maioria pode não ter cargo efetivo. Este estudo apontou também que o comprometimento normativo não foi o predominante, o que se pode presumir que a organização não pratique socialização ou que a socialização adotada não seja forte a ponto dos servidores se sentirem no dever em permanecer na empresa.

No que tange ao teste de hipóteses, a correlação entre a satisfação no trabalho e o comprometimento organizacional permitiu a aceitação de todas as hipóteses, sendo que a satisfação no trabalho se correlacionou positivamente e moderadamente com o comprometimento afetivo $(0,401)$, positivamente e fraca com o comprometimento normativo $(0,207)$ e calculativo $(0,179)$, inferindo que a satisfação no trabalho destes servidores e o comprometimento organizacional caminham juntos.

Em virtude desses valores, compreende-se que a maior correlação entre a satisfação no trabalho e o comprometimento afetivo tenha vínculos com os sentimentos de satisfação entre os servidores e chefia, como também pela identificação com a natureza do trabalho por apresentar fatores afetivos no exercício das funções, em contrapartida a fraca correlação entre a satisfação no trabalho e o comprometimento calculativo possa ser, como falado anteriormente, a indiferença dos servidores com o salário e as promoções, contudo é necessário, para uma melhor conclusão, um estudo que envolva a correlação entre as dimensões e estes comprometimentos.

Diante das considerações, sugere-se uma reavaliação de alguns aspectos que tangem aspectos salariais e promocionais, adoção de políticas de plano de carreira, cargos e salários seria um bom início, além disso, se faz necessário à organização propiciar o aumento do comprometimento afetivo, tendo em conta que o vínculo afetivo oferta benefícios importantes à instituição, enfim, fatores fundamentais que implicaram no atendimento e serviços prestados às pessoas de vulnerabilidade social do município.

Porém, constatou-se como limitação da pesquisa o tamanho da amostra, mesmo não sendo objetivo deste estudo, não poderia generalizar estes resultados para a ação social do município, tendo em vista que esta pesquisa abrangeu apenas o CRAS e serviços referenciados, ou seja, a proteção social básica. Outra limitação foi a falta de pesquisas neste tipo de organização que poderiam ofertar um bom embasamento para a pesquisa.

Como propostas para estudos futuros, propõem-se mais aprofundamento destes temas neste tipo de instituição. Sugere-se a continuidade desta pesquisa abordando também a correlação com características pessoais visto que nesta organização constatou-se a predominância de perfis similares; a ampliação de variáveis, como desempenho, qualidade e satisfação com a vida, também é viável por fornecer mais entendimento sobre o ambiente organizacional.

Do mesmo modo, seria importante conhecer quais dimensões da satisfação no trabalho propostas por Siqueira (2008) tem relação com cada base do comprometimento organizacional. Compreendendo que este estudo se caracteriza um estudo transversal, seria importante futuramente um estudo longitudinal, para assim analisar as variações, a fim de melhor compreender mudanças e se aprofundar nas relações entre a satisfação no trabalho e comprometimento organizacional.

Em suma, esta pesquisa propiciou contribuições ao meio acadêmico e organizacional/ social, acadêmico por fornecer percepções sobre as variáveis estudadas, bem como sobre a relação entre 
estas; nas contribuições organizacionais/ sociais destaca-se a oportunidade aos contribuintes de exporem suas percepções, auxiliar na identificação de aspectos a serem melhorados na organização e assim, consequentemente, aperfeiçoar o atendimento aos necessitados.

\section{Referências}

Allen, N. J., \& Meyer, J. P. (1990). The measurement and antecedents of affective, continuance and normative commitment to the organization. Journal of Occupational Psychology, 63, pp. 01-18.

Almeida, D. M. de, Lopes, L. F. D., Costa, V. M. F., Santos, R. de C. T. dos, \& Corrêa, J.S. (2016). Satisfação no trabalho dos policiais militares do Rio Grande do Sul: um estudo quantitativo. Psicologia: Ciência e Profissão, 36 (4), 801-815. Recuperado em 21 abril, 2017, de http://www.scielo.br/pdf/pcp/v36n4/1982-3703pcp-36-4-0801.pdf

Arruda, J. F., \& Rodriguez, M. R. Y. (2012). Remuneração por desempenho gera mais satisfação no colaborador? Estudo de caso de empresa comercial. In: Simpósio de Excelência em Gestão e Tecnologia, 9. Recuperado em 01 julho, 2017, de http://www.economia. aedb.br/seget/artigos12/17316107.pdf

Assunção, R. R., Domingos, S. R. M., Cabral, A. C. de A., Santos, S. M. dos, \& Pessoa, M. N. M. (2014). Satisfação e comprometimento organizacional afetivo: um estudo com docentes universitários do curso de Ciências Contábeis. Rev. Adm. UFSM, Santa Maria, 7(3), 453-468. Recuperado em 18 março, 2017, de https://periodicos.ufsm.br/reaufsm/article/view/7588/pdf

Aydogdu, S., \& Asikgil, B. (2011). An Empirical Study of the Relationship Among Job Satisfaction, Organizational Commitment and Turnover Intention. International Review of Management and Marketing, v. 1, n. 3, p. 43-53.

Azevedo, A. J. D., \& Medeiros, M. da P. M. de (2012). Satisfação no trabalho: um estudo de caso na procuradoria geral de justiça do Rio Grande do Norte. Recuperado em 17 março, 2017, de http://www. machadosobrinho.com.br/revista_online/publicacao/ artigos/Artigo02REMS6.pdf

Baotham, S., Hongkhuntod, W., \& Rattanajun, S. (2010). The Effects of Job satisfaction and Organizational Commitment on Voluntary Turnover Intentions of Thai Emplyees in the New University. Review of Business Research, v. 10, n. 1, p. 73-82.
Bastos, A. V. B. (1993). Comprometimento organizacional: um balanço dos resultados e desafios que cercam essa tradição de pesquisa. Revista de Administração de Empresas, São Paulo, 33 (3), 52-64. Recuperado em 19 abril, 2017, de http://www.scielo.br/ pdf/rae/v33n3/a05v33n3.pdf

Bastos, A. V., \& Menezes, I. G. (2010). Intenção de permanência na organização: um constituinte ou consequente do comprometimento organizacional?. Estudos de Psicologia, 15 (3), 299-307. Recuperado em 19 abril, 2017, de http://www.repositorio.ufba.br:8080/ ri/bitstream/ri/2684/1/a10v15n3.pdf

Ben-bakr, K., Al-shammari, S., Jefri, O.A., \& Prasad, J.N. (1994). Organizational Commitment, Satisfaction and Turnover in Saudi Organizations: A Predictibe Study. The Journal of Socio-Economic, v. 23, n. 4, p. 449-456.

Bergamini, C. W. (2008). Motivação nas organizações (5a ed.). São Paulo: Atlas.

Bion, E. N. (2004). Satisfação no trabalho: um estudo de caso na biblioteca da Universidade do Vale do Itajaí no campus de São José. 2004. 95 f. Relatório de conclusão de estagio (Bacharel em Automação de Escritórios e Secretariado), Universidade do Vale do Itajaí, São José. Recuperado em 17 março, 2017, de http://siaibib01. univali.br/pdf/Eloiza\%20Bion.pdf

Bonfim, T. M. do, Stefano, S. R., \& Andrade, S. M. de (2010). Satisfação e motivação do trabalbo dos servidores públicos de uma prefeitura de pequeno porte do estado do Paraná- uma analise a partir do clima organizacional. In: Seminários em Administração, 13, set. Recuperado em 25 novembro, 2016, de http://www. sgc.goias.gov.br/upload/arquivos/2013-04/area-gestaode-pessoas-satisfacao-e-motivacao-no-trabalho.pdf

Borges-Andrade, J. E., Afanasieff, R. S., \& Silva, M. S. (1989). Mensuração de comprometimento organizacional em instituições públicas. In Sociedade Brasileira de Psicologia (Org.), XIX Reunião Anual de Psicologia. Resumos (p. 236). Ribeirão Preto: Autor.

Botelho, R. D., \& Paiva, K. C. M. de (2011). Comprometimento organizacional: um estudo no Tribunal de Justiça do Estado de Minas Gerais. RAP, Rio de Janeiro, 45 (5), 1249-1283. Recuperado em 10 abril, 2017, de http://www.scielo.br/pdf/rap/v45n5/ v45n5a02

Botrel, A. M. M., Mesquita, J. M. C. de, \& Bastos, A. M. (2015). Satisfação e comprometimento dos médicos: estudo em instituições hospitalares de Minas Gerais. In: ENCONTRO DA ANPAD, 39., set. Recuperado em 05 abril, 2017, de http://www.anpad.org.br/ anpad/eventos. php?cod_evento=1\&cod_edicao_subsecao $=1198 \&$ cod_ evento_edicao=78\&cod_edicao_trabalho=20136\# 
Brandão, I. de F., Lima, L. C. de, Cabral, A. C. de A., Santos, S. M. dos, \& Pessoa, M. N. M. (2014). Satisfação no serviço público: um estudo na superintendência regional do trabalho e emprego no Ceará. REAd, Porto Alegre, 77 (1), 90-113. Recuperado em 25 novembro, 2017, de http:// www.scielo.br/pdf/read/v20n1/a04v20n1.pdf

Brasil. Ministério do Desenvolvimento Social e Combate à Fome. (2009). Orientações técnicas: Centro de Referência de Assistência Social - CRAS. Brasília: Ministério do Desenvolvimento Social e Combate à Fome.

Bruni, A. L. (2012). SPSS: guia prático para pesquisadores. São Paulo: Atlas.

Cappi, M. N., \& Araujo, B. F. V. B. de (2015). Satisfação no trabalho, comprometimento organizacional e intenção de sair: um estudo entre as gerações x e y. REAd, Porto Alegre, 82 (3), 576- 600. Recuperado em 24 fevereiro, 2017, de http://www.scielo.br/pdf/read/v21n3/14132311-read-21-03-00576.pdf

Davis, K., \& Newstrom, J. W. (2004). Comportamento humano no trabalho: uma abordagem psicológica. São Paulo: Pioneira Thomson Learning.

Demo, G., Martins, P. de R., \& Roure, P. (2013). Políticas de gestão de pessoas, comprometimento organizacional e satisfação no trabalho na livraria cultura. Revista Alcance, 20 (2), 237-254. Recuperado em 06 março, 2017, de http://search.proquest.com/op enview/762f193355107b1c90bca30285d37d09/1?pqorigsite $=$ gscholar $\& \mathrm{cbl}=2032138$

Flaviano, V., Löbler, M. L., \& Avelino, A. F. A. (2014). Satisfação e comprometimento organizacional: um estudo com membros de cooperativas agrícolas. In: ENCONTRO DA ANPAD, 38., set. Recuperado em 05 abril, 2017, de http://www.anpad.org.br/admin/ pdf/2014_EnANPAD_EOR1365.pdf

Freitas, L. L. de (2014). Influências da implementação de uma gestão estratégica no comprometimento dos empregados em organizações do terceiro setor. 215 f. Tese (Doutorado em Psicologia), Universidade Federal de Santa Catarina, Florianópolis, 2014. Recuperado em 19 abril, 2017, de https://repositorio. ufsc.br/bitstream/handle/123456789/129092/330820. pdf? sequence $=1 \&$ is Allowed $=\mathrm{y}$

Garrido, T. C. J. (2009). Satisfação no trabalho: um estudo no superior tribunal de justiça. 2009. 43 f. Monografia (Especialista em Gestão Judiciária), Universidade de Brasília, Brasília/ DF. Recuperado em 19 abril, 2017, de http:// bdm.unb.br/bitstream/10483/1542/1/2009_

TerezaCristinaJuremaGarrido.pdf

Gouveia, V. V., Milfont, T. L., Fischer, R., \& Coelho, J. A. P. de M.(2009). Teoria funcionalista dos valores humanos: aplicações para organizações. RAM, São Paulo/ SP, 10 (3), 34-59. Recuperado em 19 abril, 2017, de http://editorarevistas.mackenzie.br/index.php/RAM/ article/view/1065/778
Guimarães, V. da F. (2007). Bases de poder do supervisor, conflitos intragrupais e comprometimento organizacional e com a equipe: um estudo exploratório. 2007. 143 f. Dissertação (mestrado em Psicologia), Universidade Federal de Uberlândia, Uberlândia. Recuperado em 17 abril, 2017, de https://repositorio.ufu. br/bitstream/123456789/17274/1/VFGuimaraesDISPRT. pdf

Hedler, D. L., \& Castro, A. L. de (2015). Satisfação do Servidor Público no Trabalho: um Estudo de Caso nos Centros de Referência de Assistência Social de Paranavaí. UNOPAR Cient., Ciênc. Juríd. Empres., Londrina, 16(2), 192-198. Recuperado em 06 março, 2107, de http://pgsskroton.com.br/seer//index.php/juridicas/ article/view/3321/2991

Ladeira, W., Jr., Sonza, I. B., \& Berte, R. S. (2012). Antecedentes da satisfação no setor público: um estudo de caso na prefeitura de Santa Maria (RS). RAP, Rio de Janeiro, 46(1), 71-91. Recuperado em 24 fevereiro, 2017, de http://www.scielo.br/pdf/rap/v46n1/v46n1a05

Lima, M. B. (2013). Satisfação no trabalbo e sua correlação com o comprometimento: Um estudo com funcionários de uma associação de língua estrangeira. $74 \mathrm{f}$. Monografia (Bacharelado em Administração), Universidade de Brasília, Brasília, 2013. Recuperado em 21 abril, 2017, de http://bdm.unb.br/ bitstream/10483/5251/1/2013_MichelleBarbosaLima.pdf

Leal, P. H., Costa, B. M. do N., Cabral, A. C. de A., Santos, S. M. dos, \& Pessoa, M. N. M. (2015). Satisfação no trabalho: um estudo na universidade do estado do Rio Grande do Norte. Revista Raunp,7 (2), 106-120. Recuperado em 13 abril, 2017, de https://repositorio.unp. br/index.php/raunp/article/view/1192/713

Maciel, C. de O., \& Camargo, C. (2011). Comprometimento, Satisfação e Cooperação no Trabalho: Evidências da Primazia dos Aspectos Morais e das Normas de Reciprocidade Sobre o Comportamento. RAC, Curitiba, 15 (3), art. 4, 433-453. Recuperado em 20 fevereiro, 2017, de http://search.proquest.com/ openview/0de3eb07c9cc65c04e8e8b361b31c877/1?pqorigsite $=$ gscholar $\& \mathrm{cbl}=2028896$

Martins, V. R. C. (2010). Análise da satisfação no trabalho: estudo de caso entre os funcionários da CoPP- Coordenadoria de Proteção ao Patrimônio da Universidade de Brasília. 2010. 51 f. Monografia (Especialização em Gestão Universitária) Universidade de Brasília, Brasília/ DF, jul. Recuperado em 21 abril, 2017, de http://bdm.unb.br/bitstream/10483/1316/1/2010_ VanderleaRoqueCassianoMartins.pdf

Medeiros, C. A. F., \& Enders, W. T. (1998). Validação do modelo de conceitualização de três componentes do comprometimento organizacional (Meyer e Allen, 1991). RAC, 2 (3), 67-87. Recuperado em 20 fevereiro, 2017, de http://www.scielo.br/pdf/rac/v2n3/v2n3a05.pdf 
Meyer, J. P., Stanley, D. J., Herscovitch, L.,\& Topolnytsky, L. (2002). Affective, continuance, and normative commitment to the organization: a meta -analysis of antecedents, correlates, and consequences. Journal of Vocational Behavior. v. 61, n. 1, p. 20-52.

Michel, M. H. (2009). Metodologia e pesquisa científica em ciências sociais ( 2 a ed.). São Paulo: Atlas.

Moreira, A. D. (2003). Satisfação no trabalho: Implicações na vida pessoal. 2003.60 f.Monografia (Graduação em psicologia), Faculdade de Ciências da Saúde - FACS, Brasília/DF, jun. Recuperado em 15 abril, 2017, de http://repositorio.uniceub.br/ bitstream/123456789/2827/2/9856939.pdf

Müller, M., Rauski, E. de F., Eyng, I. S., \& Moreira, J. (2005). Comprometimento organizacional: um estudo de caso no supermercado "beta”. Revista Gestão Industrial, 1 (4), 511-518. Recuperado em 17 abril, 2017, de http:// www.pg.utfpr.edu.br/ppgep/revista/revista2005/pdf4/ RGIv01n04a10.pdf

Oliveira, B. de (2006). Comprometimento organizacional: os impactos das percepções de cultura e suporte organizacionais. $132 \mathrm{f}$. Dissertação (mestrado em Psicologia), Universidade Federal de Uberlândia, Uberlândia, 2006. Recuperado em 17 abril, 2017, de http://repositorio.ufu.br/bitstream/123456789/17122/1/ BEAOliveiraDISSPRT.pdf

Paulino, R. D., Moura, G. M. B., Vasconcelos, C. R. P. de, Alves, W., \& Torres, P. J. D. (2012). Estudo descritivo do Comprometimento Organizacional e da Satisfação com a Vida em organização não-governamental. In: EMEPRO, 8. Recuperado em 25 novembro, 2016, de http://aspta.org.br/wp-content/uploads/2013/04/ Artigo-2.pdf

Paulino, R. D., Vasconcelos, C. R. P. de, Alves, W., Neto, J. T. de O., Torres, P. J. D., \& Lima, A. É. F. (2013). Comprometimento organizacional aplicado em organizações Paraibanas. Recuperado em 23 março, 2017, de http://www.convibra.org/upload/ paper/2013/34/2013_34_7111.pdf

Peixoto, A. de L. A., Bastos, A. V. B., Soares, I.S. D., \& Lobo, J. R. (2015). Comprometimento e consentimento organizacional: um estudo da validade discriminante dos construtos. Psico-USF, Bragança Paulista, 20(1), 51-61. Recuperado em 19 abril, 2017, de http://www.scielo.br/ pdf/pusf/v20n1/1413-8271-pusf-20-01-00051.pdf

Penha, E. D. dos S., Rebouças, S. M. D. P., Abreu, M. C. Sá de, \& Parente, T. C. (2016). Percepção de responsabilidade social e satisfação no trabalho: um estudo em empresas brasileiras. REGE - Revista de Gestão, 23, 306-315. Recuperado em 24 fevereiro, 2017, de http://ac.els-cdn.com/S1809227616306075/1s2.0-S1809227616306075-main.pdf?_tid=d2ae047c0de4-11e7-abf2-00000aab0f27\&acdnat=1490066389_ eec952e9c278b263c101be064d001171
Rego, A. (2003). Comprometimento organizacional e ausência psicológica - afinal, quantas dimensões?. RAE, 43 (4). Recuperado em 18 abril, 2017, de http://www. scielo.br/pdf/rae/v43n4/v43n4a03.pdf

Rego, A., \& Souto, S. (2004a). A percepção de justiça como antecedente do comprometimento organizacional: um estudo luso-brasileiro. $R A C, 8(1), 151-177$.

Recuperado em 05 abril, 2017, de http://www.scielo.br/ $\mathrm{pdf} / \mathrm{rac} / \mathrm{v} 8 \mathrm{n} 1 / \mathrm{v} 8 \mathrm{n} 1 \mathrm{a} 08$

Rego, A., \& Souto, S. (2004b). Comprometimento organizacional em organizações autentizóticas: um estudo luso-brasileiro. RAE, 44(3). Recuperado em 09 abril, 2017, de http://bibliotecadigital.fgv.br/ojs/index. php/rae/article/view/37626/36377

Robbins, S.P. (2002). Comportamento organizacional. São Paulo: Prentice Hall.

Robbins, S.P. (2005). Comportamento organizacional (11a ed.). São Paulo: Pearson Education.

Rosa, C. da, \& Carlotto, M. S.(2005). Síndrome de Burnout e satisfação no trabalho em profissionais de uma instituição hospitalar. Rev. SBPH, Rio de Janeiro, 8(2). Recuperado em 09 abril, 2017, de http://pepsic.bvsalud. org/pdf/rsbph/v8n2/v8n2a02.pdf

Rueda, F. J. M., Santos, A. A. Angelidos, \& Lima, R. C. de. (2012). Relação entre satisfação no trabalho e clima organizacional: um estudo com trabalhadores. Boletim de Psicologia, 62(137), 129-140. Recuperado em 25 novembro, 2017, de http://pepsic.bvsalud.org/pdf/bolpsi/ v62n137/v62n136a03.pdf

Santos, F. C. F. dos (2008). Satisfação no trabalho e o comprometimento organizacional na área de comércio varejista. $44 \mathrm{f}$. Monografia (Especialista em Gestão de Pessoas), Universidade de Brasília, Brasília, 2008. Recuperado em 21 abril, 2017, de http://bdm.unb.br/bitstream/10483/1451/1/2008_ FabiolaCristinaFerreiradosSantos.pdf

Santos, E. da C. L.F. dos. (2011). Satisfação no trabalho e correlação com desempenho: um estudo no instituto do meio ambiente e dos recursos hídricos do Distrito Federal. 2011. 58 f. Monografia (Bacharelado em Administração), Universidade de Brasília, Brasília. Recuperado em 21 abril, 2017, de http://bdm.unb.br/bitstream/10483/2527/1/2011_ EduardodaCunhaLamounierFdosSantos.pdf

Schröder, L. P. (2012). A satisfação do servidor público no trabalho e o reflexo desse resultado na organização. Recuperado em 09 abril, 2017, de http://bibliodigital.unijui.edu.br:8080/xmlui/ bitstream/handle/123456789/802/ARTIGO\%20 vers $\%$ C3\%A3o\%2004-07.pdf?sequence=1

Shore, L. M., \& Martins, H. J. (1989). Job Satisfaction and Organizational Commitment in Relation to Work Performance and Turnover Intentions. Human Relations, v. 42, n. 7, p. 625-638. 
Siqueira, M. M. M. (2002). Medidas do comportamento organizacional. Estudos de Psicologia, 7, 11-18.

Recuperado em 04 abril, 2017, de http://s3.amazonaws. com/academia.edu.documents/38826081/MEDIDAS DO_COMPORTAMENTO_ORGANIZACIONAL. pdf?AWSAccessKeyId=AKIAIWOWYYGZ2Y53U L3A\&Expires $=1492751175 \&$ Signature $=$ bjCKFIAJ UaYrKb4IBKdKHY53SXo\%3D\&response-contentdisposition=inline $\% 3 \mathrm{~B} \% 20$ filename $\% 3 \mathrm{DMedidas}$ _do_ comportamento_organizacional.pdf

Siqueira, M. M. M. (2008). Medidas do comportamento organizacional: ferramentas de diagnóstico e de gestão. Porto Alegre: Artmed.

Siqueira, M. M. M., \& Gomide, S., Jr. (2014). Psicologia, organizações e trabalho no Brasil (2a. ed.). Porto Alegre: Artmed. (pp. 314-348).

Souza, I. D. da S., Reche, P. M., \& Sachuk, M. I. (2013). O comprometimento organizacional e a satisfação no trabalho em funcionários de um hospital da cidade de Umuarama - PR. Qualitas Revista Eletrônica, 14 (1). Recuperado em 06 março, 2017, de http://revista.uepb. edu.br/index.php/qualitas/article/view/1712/927

Spector, P. E. (2003). Psicologia nas organizações. São Paulo: Saraiva.

Spector, P. E. (2004). Psicologia nas organizações (2a ed.). São Paulo: Saraiva.

Supeli, A., \& Creed, P. A. (2015), The Longitudinal Relationship Between Protean Career Orientation and Job Satisfaction, Organizational Commitment, and Intention-to-Quit. Journal of Career Development, $\mathrm{p}$. 42 , n. 5, p. 1546-1569.

Tonetto, R. C. Z. (2013). A satisfação no trabalho: um estudo com servidores públicos estaduais do poder judiciário de Catuípe- RS. 57 f. TCC (Graduação em Administração) Universidade Regional do Noroeste do Estado do Rio Grande do Sul, 2013. Recuperado em 25 novembro, 2016, de http://bibliodigital.unijui.edu. br:8080/xmlui/bitstream/handle/123456789/1944/ Rosana\%20Tonetto\%20-\%20TCC\%20FINAL. pdf? sequence $=1$
Traldi, M. T. F., \& Demo, G. (2012). Comprometimento, bem-estar e satisfação dos professores de administração de uma universidade federal. REAd, Porto Alegre, 72 (2), 290-316. Recuperado em 10 abril, 2017, de http://www. seer.ufrgs.br/index.php/read/article/view/38389/24661

Vergara, S. C. (2016). Projetos e relatórios de pesquisa em administração (16a ed.). São Paulo: Atlas.

Wright, Bradley E., \&Davis, Braian S. (2003). Job satisfaction in the public sector: the role of the work environment. The American Review of Public Administration, v. 33, n. 7.

Wu, K. L., \& Melo, M. A. de S. (2016). Satisfação no trabalbo: um estudo na percepção dos trabalhadores de um órgão público municipal. In: ANAIS - Seminário de Pesquisa, Pós-Graduação, Ensino e Extensão do CCSEH - SEPE. Recuperado em 21 abril, 2017, de http://www. anais.ueg.br/index.php/sepe/article/view/7579/5068

Xavier, V. M. C. (2005). Locus de controle, comprometimento organizacional e satisfação no trabalho: um estudo correlacional. $101 \mathrm{f}$. Dissertação (mestrado em Psicologia) Universidade Federal de Uberlândia, Uberlândia, 2005. Recuperado em 06 março, 2017, de https://repositorio.ufu.br/ bitstream/123456789/17213/1/VXavierDISSPRT.pdf

Yucel, I. (2012). Examining the Relationship among Job Satisfaction, Organizational Commitment, and Turnover Intention: An Empirical Study. International Journal of Business Management, v.7, n.20, p. 44-57.
Recebido em 11 set. 2017 / aprovado em 5 mar. 2018

Para referenciar este texto

Oliveira, C. B. A., Silva, E. F., Silva, F. F., \& Paulino, R. D. Comprometimento organizacional e satisfação no trabalho: estudo com funcionários do CRAS de Borborema-PB. Exacta, São Paulo, v. 16, n. 4, p. 93-114. out./dez. 2018. Disponível em: <https://doi. org/10.5585/ExactaEP.v16n4.7821> 